\title{
Prevalence of and Factors Associated with Myopia in Inner Mongolia Medical Students in China, a cross-sectional study
}

\author{
Lan Wang ${ }^{1 \dagger}$, Maolin Du ${ }^{1 \dagger}$, He $\mathrm{Yi}^{1 \dagger}$, Shengyun Duan ${ }^{1}$, Wenfang Guo ${ }^{1}$, Peng Qin², Zhihui Hao ${ }^{3}$ and Juan Sun ${ }^{1 *}$
}

\begin{abstract}
Background: To further explore characteristics of myopia and changes in factors associated with myopia among students at Inner Mongolia Medical University.

Methods: Two cross-sectional censuses were conducted in 2011 and 2013. Participants were medical students residing on campus in 2011 and 2013. Logistic regression analysis was performed to ascertain associations with basic information, genetic factors, environmental factors. The $x^{2}$ test was used to test for differences in prevalence between 2011 and 2013. Prevalence was calculated at various myopia occurrence times among different parental myopia statuses.

Results: A total of 11,138 students enrolled from 2007 to 2012 completed the questionnaire. The prevalence of myopia in 2011 and 2013 was 70.50\% and 69.21\%, respectively, no statistically significant difference existed between the two censuses $(p=0.12)$. Both censuses were completed by 1015 students. There were no differences among the various year of study in 2011 or 2013. Myopic prevalence increased with an increased number of myopic parents: the prevalence if both parents were myopic was over $90 \%$, nearly $80 \%$ if one parent was myopic, and less than $70 \%$ with non-myopic parents $(p<0.001)$. Myopic occurrence ranked from earliest to latest was in kindergarten and primary school when both parents were myopic, in middle school when one parent was myopic, and in university when no parent was myopic. Students staying up late, using a computer more than $3 \mathrm{~h}$ per day, not performing eye exercises, using eye drops, and rubbing the eyes at high risk for myopia.
\end{abstract}

Conclusions: Myopic status was stable during the university period. Genetic factors play a major role in myopia. Protective measures are useful for university students.

Keywords: Myopia, Prevalence, Risk factors, Parent myopic, Myopia occurrence time

\section{Background}

Myopia is a significant public health problem and its prevalence is increasing over time [1]. By the year 2020, it is estimated that 2.5 billion people - one-third of the world's population - will be affected by myopia [2]. Furthermore, the prevalence of myopia has been shown to vary widely with geographic location $^{3}$. In European and North American adult populations, the prevalence of myopia is reported to be between $20 \%$ and $40 \%$ [3, 4].

\footnotetext{
* Correspondence: sj6840@163.com

${ }^{\dagger}$ Equal contributors

${ }^{1}$ Inner Mongolia Medical University, No. 5, Xinhua Street, Hohhot, Inner

Mongolia Autonomous Region 010110, China

Full list of author information is available at the end of the article
}

In Asia, the prevalence of myopia among teenagers and young adults exceeds $70 \%[5,6]$.

The etiology of myopia is multifactorial and both genes and the environment play important roles [7, 8]; myopia results from complex genetics [2, 9-12]. It has been shown that in young adults, education appear to cause increases in axial length and shifts toward increased myopia [13]. The high prevalence of myopia and high numbers of myopic university students pose particularly important public health and social problems [14]. Ocular risks associated with myopia should not be underestimated, and there is a public health need to prevent myopia onset and progression. 
Based on the above research, there have been numerous studies both on myopia prevalence and associated factors. Therefore, we used a large sample to confirm the prevalence of myopia and factors associated with myopia among all students at an Inner Mongolian medical university.

\section{Methods}

\section{Data source}

Cross-sectional censuses of the physical and mental health of university students were conducted in 2011(6044) and 2013(6109) among medical students residing on campus at the Inner Mongolia Medical College of China. The censuses included students enrolled from 2007 to 2012, covering 6 years. Some students (1015) resided on campus in 2011 and 2013; therefore, they participated in both censuses. The total number of students is 11,138 . In our school system, some students reside at school for 3 years, and others reside at school for 4 years [15]; therefore, we conducted the census twice. The two censuses employed a self-administered questionnaire. To make data expression clearer, we defined the factors newly appear in this paper, except those which had been defined in our previous studies [11, 15-17]. We also conducted a pre-survey to determine whether each factor could be accurately understood by the students and the factors which are easy to confound the data were modified. We also explained these factors in detail to the students in our census. The testretest reliability was 0.96 , which was calculated through a randomly sampled 100 students in the census [15].

\section{Census contents}

Subjects evaluated as myopic were those who used myopic spectacles or contact lenses to look at objects and gave details about the age at which they started to wear spectacles or contact lenses [18].

We investigated factors including basic information: area (urban/rural), year of study (1, 2, 3, 4 and 5), and sex (male/female); genetic factors: family members' myopic statuses (both parents, one parent, or no parent); and environmental factors: if they frequently see green (yes/no), perform eye exercises (insist on performing/ sometimes /rarely/ will not perform), use eye drops (yes/no), have an inadequate diet (yes/no), take breaks after reading $1 \mathrm{~h}$ (yes/no), use a lamp (yes/no), stay up late (yes/no), are affected by people around them staying up late (yes/no), stay up late for homework (yes/no), stay up late for study section review (yes/no), stay up late because of pressure to study (yes/no), search for information online (yes/no), when they started using a computer (primary school, high school, university), how often they used a computer (every day, 2-4 times a week, 1 time per week, almost none), how long they used a computer per day (less than $1 \mathrm{~h}, 1-$ $3 \mathrm{~h}$, more than $3 \mathrm{~h}$ ), bedtime (before 22:00, 22:00-00:00, after 00:00, no regular time), read for long durations (yes/ no), read while lying down (yes/no), read under dim light (yes/no), suffer from depression (yes/no), and if they rubbed their eyes (yes/no).

The dim light was lighting levels be below 30 footcandles (incandescent light bulbs below 40w) where the students usually reads and writes [19]. Participants excluded from the analyses included those reporting a history of cataract and/or glaucoma.

\section{Statistical analysis}

The chi-squared test was used to test for differences in myopic prevalence between 2011 and 2013 in relation to various parameters. Because there was no significant difference in myopia prevalence between 2011 and 2013, we explored factors related to myopia prevalence by merging the two censuses. Prevalence was calculated for each investigated factor and various myopia occurrence times among students according to different parental myopia statuses. Multiple-factor non-conditional logistic regression analysis was used to evaluate the significance of each factor of myopia after adjusted for possible confounding factors. Dependent variables fell into two categories: myopic and non-myopic. Independent variables on the dependent variable in the model included all investigated factors. The odds ratio (OR) and corresponding 95\% CI were calculated. In the model, ORs $>1.0$ designated increased myopic risk and ORs $<1.0$ indicated protective factors.

Microsoft Excel and SPSS 13.0 statistical software were used for data management and analysis. A statistical significance level of $p \leq 0.05$ was used throughout the study.

\section{Results}

A total of 11,138 students enrolled from 2007 to 2012 completed the questionnaire, of whom 7980 (27.3\%) were men and $3149(72.7 \%)$ were women. The mean age of the participants was $21.08 \pm 1.57$. The prevalence of myopia in 2011 and 2013 was 70.50 and 69.21, respectively, and no statistically significant difference existed between the two censuses $\left(x^{2}=2.4, p=0.12\right)$. One thousand fifteen students participated in both censuses, in which 694 myopic students were assessed in 2011, and only four myopic students were added in 2013.

Table 1 shows the baseline characteristics of the study participants and prevalence of myopia in relation to each census item. There was no difference among the various year of study in 2011 or 2013. Students' myopic prevalence when both parents were myopic was over $90 \%$; the prevalence when one parent was myopic was nearly $80 \%$; and the prevalence when both parents were non-myopic was less than $70 \%\left(x^{2}\right.$ trend test $\left.=18.23, p<0.001\right)$. Myopic prevalence increased with an increased number of 
Table 1 Prevalence of myopia among Inner Mongolia Medical University students in relation to various parameters

\begin{tabular}{|c|c|c|c|c|c|}
\hline Variable & $N=11,138$ & $n=7814$ & prevalence & $x^{2}$ & $P$ \\
\hline \multicolumn{6}{|l|}{ Basic Information } \\
\hline Sex & & & & 77.91 & 0.000 \\
\hline female & 7980 & 5792 & 72.58 & & \\
\hline male & 3149 & 2018 & 64.08 & & \\
\hline Area & & & & 76.89 & 0.000 \\
\hline Rural & 6877 & 4622 & 67.21 & & \\
\hline Urban & 4239 & 3181 & 75.04 & & \\
\hline Year of study & & & & 7.35 & 0.118 \\
\hline 1 & 4276 & 2990 & 69.93 & & \\
\hline 2 & 3935 & 2755 & 70.01 & & \\
\hline 3 & 2260 & 1615 & 71.46 & & \\
\hline 4 & 513 & 361 & 70.37 & & \\
\hline 5 & 142 & 87 & 61.27 & & \\
\hline \multicolumn{6}{|l|}{ Genetic factors } \\
\hline Family members' myopia statuses & & & & 18.23 & 0.000 \\
\hline both parents & 245 & 221 & 90.20 & & \\
\hline one parent & 1448 & 1138 & 78.59 & & \\
\hline no parent & 9445 & 6455 & 68.34 & & \\
\hline \multicolumn{6}{|l|}{ Environmental factors } \\
\hline Often see green & & & & 0.73 & 0.390 \\
\hline No & 4221 & 368 & 8.72 & & \\
\hline Yes & 6915 & 636 & 9.20 & & \\
\hline Perform eye exercises & & & & 74.83 & 0.000 \\
\hline Insist on performing & 325 & 181 & 55.69 & & \\
\hline Sometimes & 3581 & 2399 & 66.99 & & \\
\hline Rarely & 6522 & 4755 & 72.91 & & \\
\hline Will not perform & 699 & 475 & 67.95 & & \\
\hline Eye drops & & & & 38.66 & 0.000 \\
\hline No & 5993 & 4055 & 67.66 & & \\
\hline Yes & 5143 & 3758 & 73.07 & & \\
\hline People around them stay up late & & & & 4.15 & 0.042 \\
\hline No & 6957 & 4833 & 69.47 & & \\
\hline Yes & 4177 & 2978 & 71.30 & & \\
\hline Inadequate diet & & & & 8.67 & 0.003 \\
\hline No & 4748 & 3261 & 68.68 & & \\
\hline Yes & 6382 & 4548 & 71.26 & & \\
\hline Take a break after reading $1 \mathrm{~h}$ & & & & 165.41 & 0.000 \\
\hline No & 8722 & 6375 & 73.09 & & \\
\hline Yes & 2416 & 1439 & 59.56 & & \\
\hline Use a lamp & & & & 103.54 & 0.000 \\
\hline No & 2224 & 1364 & 61.33 & & \\
\hline Yes & 8913 & 6450 & 72.37 & & \\
\hline Habit of staying up late & & & & 30.95 & 0.000 \\
\hline No & 5330 & 3607 & 67.67 & & \\
\hline Yes & 5797 & 4203 & 72.50 & & \\
\hline
\end{tabular}


Table 1 Prevalence of myopia among Inner Mongolia Medical University students in relation to various parameters (Continued)

\begin{tabular}{|c|c|c|c|c|c|}
\hline \multicolumn{4}{|c|}{ Stay up late for homework } & \multirow[t]{2}{*}{9.61} & \multirow[t]{2}{*}{0.002} \\
\hline No & 5398 & 3712 & 68.77 & & \\
\hline Yes & 5735 & 4098 & 71.46 & & \\
\hline \multicolumn{4}{|c|}{ Stay up late for study section review } & \multirow[t]{3}{*}{1.67} & \multirow[t]{3}{*}{0.195} \\
\hline No & 7869 & 5492 & 69.79 & & \\
\hline Yes & 3265 & 2319 & 71.03 & & \\
\hline \multicolumn{4}{|c|}{ Stay up late because of pressure to study } & \multirow[t]{3}{*}{0.81} & \multirow[t]{3}{*}{0.370} \\
\hline No & 6023 & 4717 & 78.32 & & \\
\hline Yes & 5111 & 3640 & 71.22 & & \\
\hline \multicolumn{4}{|c|}{ Search for information online } & \multirow[t]{3}{*}{17.01} & \multirow[t]{3}{*}{0.000} \\
\hline No & 3200 & 2155 & 67.34 & & \\
\hline Yes & 7936 & 5658 & 71.30 & & \\
\hline \multicolumn{4}{|c|}{ When they started using a computer } & \multirow[t]{4}{*}{3.48} & \multirow[t]{4}{*}{0.180} \\
\hline Primary school & 1118 & 804 & 71.91 & & \\
\hline High school & 5470 & 3860 & 70.57 & & \\
\hline University & 4532 & 3143 & 69.35 & & \\
\hline \multicolumn{4}{|c|}{ Frequency of computer use } & \multirow[t]{5}{*}{3.1} & \multirow[t]{5}{*}{0.380} \\
\hline Every day & 3359 & 2344 & 69.78 & & \\
\hline 2-4 times a week & 4025 & 2814 & 69.91 & & \\
\hline 1 time per week & 2206 & 1544 & 69.99 & & \\
\hline Almost none & 1537 & 1108 & 72.09 & & \\
\hline \multicolumn{4}{|c|}{ Computer use per day } & \multirow[t]{4}{*}{4.17} & \multirow[t]{4}{*}{0.125} \\
\hline Less than $1 \mathrm{~h}$ & 3270 & 2338 & 71.50 & & \\
\hline $1-3 h$ & 6098 & 4259 & 69.84 & & \\
\hline More than $3 \mathrm{~h}$ & 1753 & 1210 & 69.02 & & \\
\hline \multicolumn{4}{|l|}{ Bedtime } & \multirow[t]{5}{*}{31.04} & \multirow[t]{5}{*}{0.000} \\
\hline Before $10: 00$ & 283 & 157 & 55.48 & & \\
\hline 10:00-12:00 & 8156 & 5776 & 70.82 & & \\
\hline After 12:00 & 1961 & 1367 & 69.71 & & \\
\hline No rule & 730 & 511 & 70.00 & & \\
\hline Read for long dura & & & & 1586.92 & 0.000 \\
\hline No & 5906 & 3250 & 55.03 & & \\
\hline Yes & 5086 & 4557 & 89.60 & & \\
\hline Read while lying $d$ & & & & 9.26 & 0.002 \\
\hline No & 2246 & 1517 & 67.54 & & \\
\hline Yes & 8886 & 6294 & 70.83 & & \\
\hline Read under dim lic & & & & 3.84 & 0.050 \\
\hline No & 2374 & 1627 & 68.53 & & \\
\hline Yes & 8758 & 6184 & 70.61 & & \\
\hline Depression & & & & 8.32 & 0.004 \\
\hline No & 5270 & 3628 & 68.84 & & \\
\hline Yes & 5860 & 4181 & 71.35 & & \\
\hline Eye rubbing & & & & 19.04 & 0.000 \\
\hline No & 2752 & 1840 & 66.86 & & \\
\hline Yes & 8379 & 5970 & 71.25 & & \\
\hline
\end{tabular}


myopic parents according to the $\chi^{2}$ trend test. The prevalence of myopia was higher among women living in the city. The prevalence of myopia was also higher among students with staying up late, using a computer, lack of concern for eye health, lying down while reading, reading for a long duration, and going to bed after 10:00.

Table 2 shows the myopia statuses of the students. The results suggest that nearly $80 \%$ began wearing spectacles in middle school. Regarding the type of glasses, more than $80 \%$ wore frame glasses and more than half chose them in an eyeglasses store. Among myopic students, 53.44\% envied normal vision and 56.91\% felt eye fatigue. The attitude of $60 \%$ of myopic students was open to trying treatment.

We included all factors in binary logistic regression models (Table 3). Students with one or two myopic parents were at high risk for myopia. Women who lived in the city with staying up late, using a computer more than $3 \mathrm{~h}$ per day, not performing eye exercises, using eye drops, rubbing their eyes were at high risk for myopia. Taking a

Table 2 The myopia statuses of students at Inner Mongolia Medical University

\begin{tabular}{|c|c|c|c|c|}
\hline Category & $n=7814$ & prevalence & $x^{2}$ & $p$ \\
\hline $\begin{array}{l}\text { When they began wearing } \\
\text { spectacles }\end{array}$ & & & $17,197.49$ & 0.000 \\
\hline Kindergarten & 54 & 0.69 & & \\
\hline Primary school & 687 & 8.79 & & \\
\hline Middle school & 6108 & 78.17 & & \\
\hline University & 965 & 12.35 & & \\
\hline \multicolumn{3}{|c|}{ Where they were fitted for spectacles } & 6525.73 & 0.000 \\
\hline Ophthalmic hospital & 2968 & 37.98 & & \\
\hline Eyeglasses Store & 5178 & 66.27 & & \\
\hline Both & 332 & 4.25 & & \\
\hline \multicolumn{5}{|l|}{ Glasses Type } \\
\hline Contact lenses & 278 & 3.56 & $18,286.13$ & 0.000 \\
\hline Frame glasses & 6476 & 82.88 & & \\
\hline Both & 794 & 10.16 & & \\
\hline Do not wear glasses & 385 & 4.93 & & \\
\hline Views on myopia & & & 1983.44 & 0.000 \\
\hline Worried about genetics & 2805 & 35.90 & & \\
\hline Lack of confidence & 2076 & 26.57 & & \\
\hline Envy normal vision & 4176 & 53.44 & & \\
\hline Eye fatigue & 4447 & 56.91 & & \\
\hline Views on treating myopia & & & 5201.18 & 0.000 \\
\hline Willing to try treatment & 4681 & 59.91 & & \\
\hline $\begin{array}{l}\text { No need to be overly } \\
\text { concerned }\end{array}$ & 2815 & 36.03 & & \\
\hline Do not care & 427 & 5.46 & & \\
\hline
\end{tabular}

Table 3 Results of the logistic regression analysis on myopia among medical students

\begin{tabular}{llll}
\hline & $P$ & OR & $95 \% \mathrm{Cl}$ \\
\hline $\begin{array}{l}\text { Sex } \\
\text { female } \\
\text { male }\end{array}$ & & 1 & \\
$\begin{array}{l}\text { Area } \\
\text { Rural }\end{array}$ & 0.000 & 0.64 & $0.58-0.71$ \\
$\begin{array}{l}\text { Urban } \\
\text { Family members' myopia statuses }\end{array}$ & 0.000 & 1.14 & $1.03-1.27$ \\
father & 0.000 & 1.71 & $1.41-2.08$ \\
mother & 0.001 & 1.37 & $1.13-1.67$
\end{tabular}

Take a break after reading $1 \mathrm{~h}$

No

Yes

0.000

0.56

$0.50-0.63$

Reading under a dim lamp

No

Yes

1.47

$1.31-1.64$

Habit of staying up late

No

Yes

0.000

Perform eye exercises

Insist on performing

Sometimes

0.13

0.13

Rarely

0.72

Do not perform

0.0

Computer use per day

Less than $1 \mathrm{~h}$

1-3 h

0.00

More than $3 \mathrm{~h}$

0.03

1.33

$1.14-1.55$

Bedtime

Before 10:00

10:00-12:00

After 12:00

0.123

$0.59-1.19$

No rule

0.926

0.96-1.41

Often see green

No

Yes

0.001

$1.06-1.29$

Stay up to for search for information online

No

Yes

0.01

1.15

$1.03-1.29$

Eye rubbing

No

Yes

0.02

1.13

$1.02-1.26$

Eye drops

No

Yes

0.001

$\mathrm{Cl}$ confidence interval 
break after reading for $1 \mathrm{~h}$ and not reading under a dim lamp were protective factors.

Table 4 shows the time at which myopia occurred among students with different parental myopia statuses. The occurrence time of student myopia was earliest in kindergarten and primary school when both parents were myopic. The occurrence time of student myopia ranked second in middle school when one parent was myopic. The occurrence time was latest in university when neither parent was myopic.

\section{Discussion}

Compared with the reported prevalence of myopia among the general population in Western countries, the prevalence of myopia in our study was considerably higher [20, 21]. Compared with medical students in other countries, the prevalence of myopia in our study was also higher [22, 23].

We performed two censuses of all students residing on the university campus in 2011 and 2013. There was no statistically significant difference between the two censuses in myopic prevalence. Further, the myopic prevalence of students who participated in both censuses was nearly unchanged. The prevalence of myopia was not significantly different from year of study 1 to year of study 5 in 2011 or 2013. The results suggest that myopic status was stable and did not significantly change during the university period. A study among university students was consistent with our result [14]. The results may be explained by genetic factors. Students' myopic prevalence when both parents were myopic, when one parent was myopic, and when both parents were non-myopic showed a dose-dependent relationship. It showed that the majority of myopia cases within populations are caused by hereditary factors. In addition, the occurrence time of student myopia was the earliest in kindergarten and primary school when both parents were myopic. The occurrence time of student myopia was second earliest in middle school when one parent was myopic. Student myopia occurred latest in university when no parent was myopic. It clarified that student myopia occurs earlier with an increased number of myopic parents. Several studies have suggested relationships between heredity and myopia [2, 9]. Our results are consistent with their conclusions and confirmed that people were more likely to develop myopia earlier because of heredity from myopic parents [9].

While genetic factors play a major role, environmental factors also play a role in lens thickness changes, but do not change myopic status [12]. A previous study confirmed that environmental change causes myopia [12]. We further explored myopiarelated environmental factors among 11,138 students. In our study, taking a break after reading $1 \mathrm{~h}$ and not studying under a dim lamp had protective effects on eye health. It clarified that a healthy lifestyle played a protective role in university students. On the contrary staying up late, using a computer more than $3 \mathrm{~h}$ per day, not performing eye exercises, using eye drops, and rubbing the eyes could increase the thickness of the glasses. Moreover, it was demonstrated that some protective measures were useful for medical university students and could prevent further increases in the thickness of their glasses.

\section{Conclusions}

Myopic status was stable during the university period. Genetic factors play a major role in myopia. Taking a break after reading $1 \mathrm{~h}$ and not studying under a dim lamp had protective effects on eye health. Staying up late, using a computer more than $3 \mathrm{~h}$ per day, not performing eye exercises, using eye drops, and rubbing the eyes could increase the thickness of the glasses and all above can effectively change through education, so university administrators should provide systematic education to enhance it in university students.

\section{Limitation}

In our study, we did not perform an eye examination for all students; thus, "myopic" was defined according to the individual student's report that they "myopic used spectacles or contact lenses either occasionally or frequently" during our study. Therefore, the prevalence of myopia may be lower because some slightly myopic students may choose not to wear glasses.

Table 4 Student myopia occurrence time among different parental myopia statuses

\begin{tabular}{|c|c|c|c|c|c|c|c|c|}
\hline \multirow[b]{2}{*}{ Occurrence time } & \multicolumn{2}{|c|}{ father } & \multicolumn{2}{|c|}{ mother } & \multicolumn{2}{|c|}{ both myopic } & \multicolumn{2}{|c|}{ both non-myopic } \\
\hline & $\mathrm{n}$ & $\%$ & $\mathrm{n}$ & $\%$ & $\mathrm{n}$ & $\%$ & $\mathrm{n}$ & $\%$ \\
\hline Kindergarten & 5 & 0.82 & 2 & 0.38 & 2 & 0.90 & 45 & 0.70 \\
\hline Primary school & 88 & 14.43 & 70 & 13.26 & 81 & 36.65 & 448 & 6.94 \\
\hline Middle school & 501 & 82.13 & 437 & 82.77 & 129 & 58.37 & 5041 & 78.09 \\
\hline University & 16 & 2.62 & 19 & 3.60 & 9 & 4.07 & 921 & 14.27 \\
\hline total & 610 & 100.00 & 528 & 100.00 & 221 & 100.00 & 6455 & 100.00 \\
\hline
\end{tabular}




\section{Funding}

This study was supported by the Natural Science Foundation of Inner Mongolia in China, No. 2013MS1193.

\section{Availability of data and materials}

All the data supporting our findings is contained within the manuscript.

\section{Authors' contributions}

The work presented here was carried out in collaboration between all authors. JS and MD defined the research theme and methods. LW designed the questionnaire, analyzed the data, interpreted the results, and wrote the paper. HY and SD co-worked on associated data collection and their interpretation. WG and PQ discussed analyses, interpretation, and presentation. ZH carried out the survey and also helped write the paper. All authors have read and approved the final manuscript

\section{Competing interests}

The authors declare that they have no competing interests.

\section{Consent for publication}

Not applicable

\section{Ethics approval and consent to participate}

The project was approved by the Ethical Committee of Inner Mongolia Medical University, and the reference number was "YKD2017289"; participants' written informed consent was obtained.

\section{Publisher's Note}

Springer Nature remains neutral with regard to jurisdictional claims in published maps and institutional affiliations.

\section{Author details}

'Inner Mongolia Medical University, No. 5, Xinhua Street, Hohhot, Inner Mongolia Autonomous Region 010110, China. ${ }^{2}$ Hohhot University for Nationalities, Hohhot, Inner Mongolia, China. ${ }^{3}$ Inner Mongolia People's Hospital, Hohhot, Inner Mongolia, China.

Received: 24 November 2015 Accepted: 20 April 2017

Published online: 24 April 2017

\section{References}

1. Yu L, Li ZK, Gao J, Liu J, Xu C. Epidemiology, genetics and treatments for myopia. Int J Ophthalmol. 2011;6:658-69.

2. Wojciechowski R. Nature and nurture: the complex genetics of myopia and refractive error. Clin Genet. 2011;79:301-20.

3. Vitale S, Sperduto RD, Ferris FL. Increased prevalence of myopia in the United States between 1971-1972 and 1999-2004. Arch Ophthalmol. 2009;127:1632-9.

4. Jobke $S$, Kasten $E$, Vorwerk $C$. The prevalence rates of refractive errors among children, adolescents, and adults in Germany. Clin Ophthalmol. 2008;2:601-7.

5. Zhu MM, Yap MK, Ho DW, Fung WY, Ng PW, Gu YS, et al. Investigating the relationship between UMODL1 gene polymorphisms and high myopia: a case-control study in Chinese. BMC Med Genet. 2012;13:64.

6. You QS, Wu LJ, Duan JL, Luo YX, Liu LJ, Li X, et al. Factors associated with myopia in school children in China: the Beijing Childhood Eye Study. PLoS One. 2012;7:e52668.

7. Guggenheim JA, McMahon G, Northstone K, Mandel Y, Kaiserman I, Stone RA, et al. Birth order and myopia. Ophthalmic Epidemiol. 2013;20:375-84.

8. Morgan I, Rose K. How genetic is school myopia? Prog Retin Eye Res. 2005;24:1-38

9. Foster PJ, Jiang Y. Epidemiology of myopia. Eye. 2014;28:202-8.

10. Ahmed I, Mian S, Mudasir S, Andrabi Kl. Prevalence of myopia in students of Srinagar City of Kashmir, India. Int J Health Sci (Qassim). 2008:2:77-81.

11. Wu Y, Yi H, Liu W, Jia H, Eshita Y, Wang S, et al. Risk factors for myopia in Inner Mongolia medical students in China. Open J Epidemiol. 2012;2:83-9.

12. Saw SM, Chan YH, Wong WL, Shankar A, Sandar M, Aung T, et al. Prevalence and risk factors for refractive errors in the Singapore Malay eye survey. Ophthalmology. 2008;115:1713-9.

13. French AN, Morgan IG, Mitchell P, Rose KA. Risk factors for incident myopia in Australian schoolchildren: the Sydney Adolescent Vascular and Eye Study. Ophthalmology. 2013;120:2100-8
14. Sun J, Zhou J, Zhao P, Lian J, Zhu H, Zhou Y, et al. High prevalence of myopia and high myopia in 5060 Chinese university students in Shanghai. Invest Ophthalmol Vis Sci. 2012;53:7504-9.

15. Bian J, Du M, Liu Z, Fan Y, Eshita Y, Sun J. Prevalence of and factors associated with daily smoking among Inner Mongolia medical students in China: a cross-sectional questionnaire survey. Subst Abuse Treat Prev Policy. 2012;7:20.

16. Chen J, Yi H, Liu Z, Fan Y, Bian J, Guo W, et al. Factors associated with being overweight among inner mongolia medical students in china. BMJ Open. 2013:3(2):e003900

17. Sun J, He Y, Liu Z, Yan W, Jiang B, Wu Y, et al. Factors associated with skipping breakfast among inner mongolia medical students in china. BMC Public Health. 2013;13(1):1-8.

18. Low W, Dirani M, Gazzard G, Chan YH, Zhou HJ, Selvaraj P, et al. Family history, near work, outdoor activity, and myopia in Singapore Chinese preschool children. Br J Ophthalmol. 2010;94:1012-6.

19. Knirk FG. Acoustical and Visual Environments Affect Learning. Audiov Instr. 1970:15(8):34-5.

20. Vitale S, Ellwein L, Cotch MF, Ferris FL 3rd, Sperduto R. Prevalence of refractive error in the United States, 1999-2004. Arch Ophthalmol. 2008;126:1111-9.

21. Wolfram C, Höhn R, Kottler U, Wild P, Blettner M, Bühren J, et al. Prevalence of refractive errors in the European adult population: the Gutenberg Health Study (GHS). Br J Ophthalmol. 2014;98:857-61.

22. Onal S, Toker E, Akingol Z, Arslan G, Ertan S, Turan C, et al. Refractive errors of medical students in Turkey: one year follow-up of refraction and biometry. Optom Vis Sci. 2007;84:175-80.

23. Mozolewska-Piotrowska K, Stepniewska J, Nawrocka J. Frequency and incidence of myopia among medical students. Klin Ocz. 2005;107:468-70.

\section{Submit your next manuscript to BioMed Central and we will help you at every step:}

- We accept pre-submission inquiries

- Our selector tool helps you to find the most relevant journal

- We provide round the clock customer support

- Convenient online submission

- Thorough peer review

- Inclusion in PubMed and all major indexing services

- Maximum visibility for your research

Submit your manuscript at www.biomedcentral.com/submit
Biomed Central 